\title{
VOLUME OF ALCOHOL CONSUMPTION, PATTERNS OF DRINKING AND BURDEN OF DISEASE IN SUB-SAHARAN AFRICA, 2002
}

\author{
Michael Roerecke ${ }^{1,2,3}$ Isidore S. Obot ${ }^{4} \quad$ Jayadeep Patra $^{1,2} \quad$ Jürgen Rehm ${ }^{1,2,3}$ \\ ${ }^{1}$ Centre for Addiction and Mental Health, Toronto, Canada; \\ ${ }^{2}$ Department of Public Health Sciences, University of Toronto, Canada; \\ ${ }^{3}$ Research Institute for Public Health and Addiction, Zurich, Switzerland; \\ ${ }^{4}$ Department of Psychology, University of Uyo, Uyo, Nigeria
}

\begin{abstract}
The aim of this study was to provide an overview of the volume of alcohol consumption, type of beverage, patterns of drinking and alcohol-attributable burden of disease among adults in subSaharan Africa (SSA) for the year 2002. Exposure data were taken from surveys, the World Health Organization (WHO) Global Status Report on Alcohol and the WHO Global Alcohol Database. Mortality and disability data were obtained directly from WHO. The results showed that adult per capita alcohol consumption (population15 years and above) in SSA was higher than the global consumption rate $(7.4 \mathrm{~L}$ vs. $6.2 \mathrm{~L})$ and that alcohol consumption per adult drinker was $42 \%$ higher than the global rate. Alcohol was responsible for a considerable disease burden: $2.2 \%$ of all deaths and $2.5 \%$ of all DALYs could be attributed to this exposure. Intentional and unintentional injuries accounted for $53 \%$ of all alcohol-attributable deaths and almost $57 \%$ of alcohol-attributable disease burden. Among men 70\% of all alcohol-attributable injury deaths occurred among 15-44 year olds (52\% among women). This first attempt to quantify the health burden attributable to alcohol in SSA provides evidence of the direct health costs associated with drinking in the continent. In light of known effective and cost-effective measures, there is urgent need to implement interventions aimed at reducing levels of risky drinking and the high burden of alcohol-related harm in African countries.
\end{abstract}

KEY WorDs: alcohol consumption, patterns of drinking, sub-Saharan Africa, burden of disease

\section{INTRODUCTION}

Alcohol consumption is an important risk factor for burden of disease and social harm worldwide (Rehm et al., 2004; Rehm et al., 2003b). Being a causal factor for more than 60 diseases and conditions, alcohol consumption globally accounted for $3.2 \%$ of all deaths and $4.0 \%$ of all disability adjusted life years (DALYs) in 2000, with considerable variation in consumption and related harm by region (Rehm et al., 2004).

The World Health Organization (WHO) Comparative Risk Assessment Study in 2000

Corresponding author: Michael Roerecke, Social, Prevention and Health Policy Research Department, Centre for Addiction and Mental Heath, 33 Russell Street, Room \# T-425 Toronto Ontario, Canada M5S 2S1. Tel: (416) 535-8501 ext.6907, Fax: (416) 260-4156, E-mail: m.roerecke@web.de 
(CRA 2000; Rehm et al., 2004; Rehm et al., 2003b) showed that alcohol plays a significant factor in determining burden of disease in Africa. Despite high abstention rates in some parts, Africa showed the highest average alcohol consumption per drinker worldwide, and detrimental drinking patterns second only to Eastern Europe (Rehm et al., 2004). Being traditionally part of the culture in many African countries for a long time, alcohol consumption and resulting damage seem to have increased recently, especially among youths (Morojele, Flisher.A.J., \& Parry, 2005; Obot, 2005).

Compared to Western Europe and North America, psychoactive substance use (especially alcohol) epidemiology is a recent research tradition in most African countries, and one that is still lacking in many ways. Though interest in different categories of psychoactive substances has grown in recent years, most attention has traditionally been devoted to alcohol, with a focus mainly on surveys of drinking among young people (especially students in secondary or tertiary institutions) and clients of psychiatric or general hospitals (Obot, 2005). These studies and a few surveys in the general population have helped to confirm the observations that high proportions of sub-Saharan Africans abstain from drinking (e.g., Obot, 1993; Obot, 2007); of those that use psychoactive substances, alcohol is the most used of all psychoactive substances (Gureje et al., 2007; Parry, 2005), and those who drink often drink to intoxication (Obot, 1993; Pan, 1975; Partanen, 1990). This pattern of heavy episodic drinking, often associated with negative impact on population health, remains the defining feature of alcohol consumption in most of Africa today. Yet lacking in the literature on the culture of drinking in Africa are studies that relate this deleterious drinking pattern to health and social problems. In terms of specific health and social consequences of harmful consumption, reports from a few countries point to links with problems like crime, injury, violence and chronic disease conditions (Gureje et al., 2007; Obot, 2007; Parry, 2005). However, with South Africa being the exception (Schneider et al., 2007), little is known about the nature and strength of these associations and reliable population level estimates are sorely lacking.

Based on an update of the Global Burden of Disease Study estimates (Rehm et al., 2004), this study reports the latest estimates of alcohol consumption and attributable harm in terms of mortality, years of life lost (YLLs) and disability adjusted life years (DALYs) in sub-Saharan Africa in comparison to worldwide estimates for the year 2002 (Rehm et al., 2006).

\section{METHOD}

\section{Definition of Regions}

The regional distribution used in this study was defined by the WHO (2000) on the basis of very high, high, low, or very low levels of adult and of infant mortality. The relevant regions for sub-Saharan Africa are displayed in Table 1.

Table 1. Classification of countries in WHO African sub-Saharan regions by childhood and adult mortality (WHO, 2000)

\begin{tabular}{lll}
\hline \multicolumn{1}{c}{ Africa D } & & \multicolumn{1}{c}{ Africa E } \\
\cline { 1 - 1 } high child mortality and high adult mortality & & high child mortality and very high adult mortality \\
Verde, Chad, Comoros, Equatorial Guinea, Gabon, & & Congo, Côte d'Ivoire, Democratic Republic of the \\
Gambia, Ghana, Guinea, Guinea-Bissau, Liberia, & & Congo, Eritrea, Ethiopia, Kenya, Lesotho, Malawi, \\
Madagascar, Mali, Mauritania, Mauritius, Niger, & & Mozambique, Namibia, Rwanda, South Africa, \\
Nigeria, Sao Tome and Principe, Senegal, Seychelles, \\
Sierra Leone, Togo
\end{tabular}

Note: The regional sub-groupings used were defined by WHO (World Health Report 2000) on the basis of high, medium or low levels of adult and of infant mortality; sub-Saharan region excludes Algeria. 
Within Africa, only categories D (high child and high adult mortality) and E (high child and very high adult mortality) are relevant here, as WHO categorized Africa into these two subregions (World Health Organization, 2002). Due to heterogeneity within African sub-regions, this paper deals only with countries in sub-Saharan Africa, therefore excluding Algeria, which is part of WHO African sub-region D.

\section{Exposure Estimates: Key Indicators of Alcohol Consumption at Country and Regional Levels}

There are three principal sources of data for adult (people 15 years old and above) per capita estimates: national government data, data from the Food and Agriculture Organization of the United Nations (FAO) and data from the alcohol industry (Rehm et al., 2003a). Where available, the best and most reliable data generally stem from national governments, usually based on sales figures, tax revenue, and/or production data. Generally, sales data are considered the most accurate, provided that sales of alcoholic beverages are separated from sales of any other possible items sold at a given location, and that sales data are beverage specific. One of the drawbacks of production data is that they are always dependent on accurate export and import data, as otherwise the production figures will yield an under- or an overestimation. The main preferred beverage and its volume of recorded consumption were obtained from the Global Alcohol Database (GAD; World Health Organization, 2006). Beverage information for unrecorded consumption was taken from the GlobalStatusReportonAlcohol(countryprofiles; World Health Organization, 2004). Unrecorded consumption stems from a variety of sources: home production of alcoholic beverages; illegal production and sale of alcoholic beverages; illegal and legal import of alcoholic beverages; other production and use of alcoholic beverages, not taxed and/or part of the official production and sales statistics (Giesbrecht, Greenfield, Lemmens, \& Österberg, 2000).

Two dimensions of alcohol with relevance to disease outcome were included: average volume of alcohol consumption - using age- and sex- specific estimates - and a summary score for patterns of drinking. Sex- specific estimates of drinking pattern scores were not available for the present study. The exact procedures used to estimate exposure to alcohol are described in detail elsewhere (Rehm et al., 2004; Rehm et al., 2001; Rehm et al., 2003a).

In brief, prevalence of average volume of drinking was estimated in four sex-specific drinking categories by age and country. These were defined as: abstainer; drinking category I: women 2.5 to $<20 \mathrm{~g} / \mathrm{day}$; men 2.5 to $<40 \mathrm{~g}$; drinking category II: women 20 to $<40 \mathrm{~g}$; men 40 to $<60 \mathrm{~g}$; drinking category III: women $>40 \mathrm{~g}$; men $>60 \mathrm{~g}$. Average volume of alcohol consumption prevalence rates were estimated by country using a triangulation of adult per capita data and general population survey results (Rehm et al., 2004; Rehm et al., 2001; Rehm et al., 2003a), mostly taken from the GAD (World Health Organization, 2006).

Overall, we had the following data available on exposure: per capita consumption data from all countries, mainly based on FAO estimates from statistics on production, export and import (Rehm et al., 2003a; Rehm, Klotsche, \& Patra, 2007). Survey data were available at least on abstention and some indicator of drinking volume for $55 \%$ on the countries covering $62 \%$ on the population. Pattern data from surveys which allowed optimal scaling (see Rehm et al., 2004), were available from $11 \%$ of the countries covering $29 \%$ of the population. Expert judgments on patterns of drinking were available from more of the countries for a total of $39 \%$ of the population. Data on unrecorded consumption was estimated based on surveys for about $1 / 4(24 \%)$ of the countries. A score reflecting riskiness of cultural drinking pattern was calculated for each country using triangulation of general population results and key informant surveys relating to the extent that alcohol was consumed in heavy drinking occasions, without meals and in public places (Rehm et al., 2004; Rehm et al., 2001; Rehm et al., 2003a). Uncertainty of the estimates for each dimension was also quantified (World Health Organization, 2002), consistent with the general approach of the GBD in 2000 (Rehm et al., 2004) 


\section{Disease Outcome Categories and Estimates}

Three main outcomes were considered: number of deaths and burden of disease as measured in years of live lost due to premature mortality(YLLs) and disability adjusted lifeyears (DALYs). The latter measure combines years of live lost because of premature death with years of life lived with a disability (YLD) to obtain a summary measure (for general definitions see Murray, 1996). To give an example: if a male dies at age 40, one would assign the number of years up to his expected life expectancy as YLLs, where for reasons of comparability the life expectancy of Japan was used. Similarly, if a person had an accident and would be paraplegic for the rest of his life, he would lose every year 0.5 DALYs, based on the specific disability weight for this disease. Estimates for mortality and direct disease burden for the year 2002 were directly obtained from WHO Headquarters (Dr. C. Mathers) and population data were obtained from United Nations (2004).

Health outcome categories followed the definitions used in the CRA 2000 and were defined to be consistent across several risk factors (Ezzati, Lopez, Rodgers, \& Murray, 2004). They corresponded to the causes used for the 2000 GBD Study (Mathers, Vos, Lopez, Salomon, \& Ezzati, 2001; Rehm \& Gmel, 2001). The 2000 GBD disease categories used were broader than the International Classification of Diseases (ICD) codes.

\section{Risk Relations}

Alcohol consumption was found to be related to the following GBD categories: low birth weight, mouth and oropharyngeal cancer, oesophageal cancer, liver cancer, breast cancer, unipolar major depression, epilepsy, alcohol use disorders, hypertensive disorders, ischemic heart disease (IHD), cerebrovascular disease, diabetes mellitus, cirrhosis of the liver, motor vehicle accidents, drownings, falls, poisonings, selfinflicted injuries, and homicide (Mathers et al., 2001; Rehm et al., 2004; Rehm et al., 2003b).

For most chronic disease categories, alcoholattributable fractions (AAFs) of disease were derived from combining prevalence of exposure and relative risk estimates based on meta-analyses (Cho et al., 2004; Corrao, Bagnardi, Zambon, \& La Vecchia, 2004; English et al., 1995; Gutjahr, Gmel, \& Rehm, 2001; Rehm et al., 2003a; Ridolfo \& Stevenson, 2001). The following formula was used to calculate the attributable fraction (Walter, 1976; Walter, 1980):

$$
A F=\left[\sum_{i=1}^{k} P_{i}\left(R R_{i}-1\right)\right] /\left[\sum_{i=0}^{k} P_{i}\left(R R_{i}-1\right)+1\right]
$$

Where

i: exposure category with baseline exposure or no exposure $\mathrm{i}=0$

$\mathrm{RR}(\mathrm{i})$ : relative risk at exposure level $\mathrm{i}$ compared to no consumption

$\mathrm{P}(\mathrm{i})$ : prevalence of the $\mathrm{i}^{\text {th }}$ category of exposure

Sex and age-specific prevalence of exposure to alcohol consumption for each disease were multiplied with the excess risk for disease derived from meta-analyses. The number of cases (deaths, YLLs or DALYs) were then summed up and divided by the number of all cases of a disease to derive the fraction of deaths, YLLs or DALYs attributable to alcohol exposure. As derived from the formula above, AAFs can be interpreted as reflecting the proportion of disease that would disappear if there had been no alcohol consumption. For depression and injuries, AAFs were taken from the CRA 2000 study (see Rehm et al. (2004) for a detailed description of underlying assumptions and calculations). Beneficial effects of alcohol consumption on ischaemic heart disease, strokes and diabetes were not estimated for African sub-regions due to the evidence that the pattern of drinking for most alcohol consumption is not beneficial in these regions (for physiological mechanisms: McKee \& Britton, 1998; Puddey, Rakic, Dimmitt, \& Beilin, 1999; Rehm, Sempos, \& Trevisan, 2003; for epidemiological evidence: Gmel, Rehm, \& Kuntsche, 2003; Rehm et al., 2004).

\section{RESULTS}

There was considerable variation in levels of overall per capita alcohol consumption among 


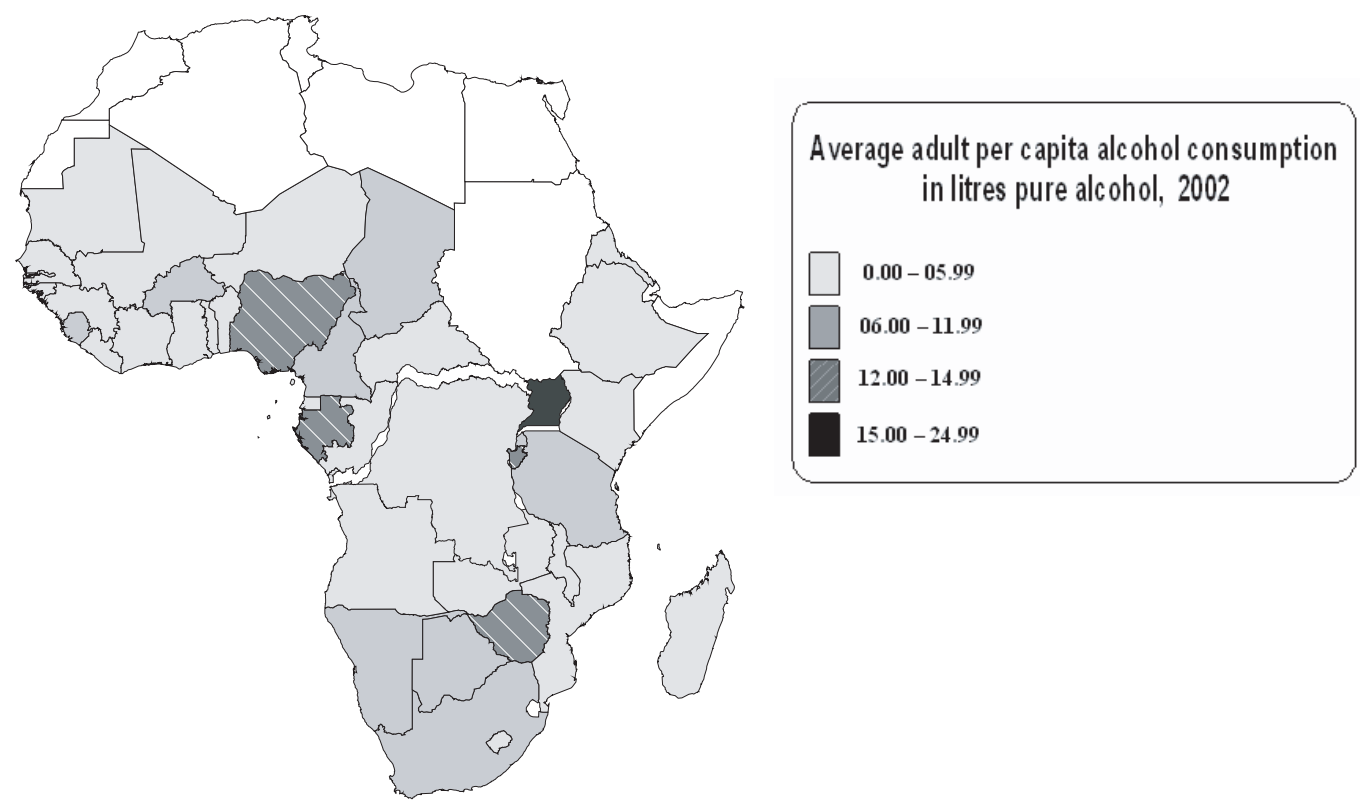

Figure 1. Adult per capita recorded and unrecorded alcohol consumption in litres of pure alcohol, sub-Saharan Africa, 2002

Note: Blank countries are not part of sub-Saharan Africa.

sub-Saharan African countries. As shown in Figure 1, the highest overall adult per capita recorded and unrecorded alcohol consumption for the year 2002 was estimated in Uganda (18.6 L) followed by Nigeria (14.1 L), Burundi (14.0 L), Zimbabwe (13.5 L), and Gabon (12.2 L). This contrasts with the lowest levels of alcohol consumption which were estimated in countries such as Mauritania $(0.01 \mathrm{~L})$, Niger $(0.1 \mathrm{~L})$ and Guinea $(0.2 \mathrm{~L})$.

Table 2 gives an overview of recorded and unrecorded per capita alcohol consumption and main type of beverage in the two African subregions comprising sub-Saharan Africa (SSA).

The population-weighted average per adult capita alcohol consumption in SSA was 7.4 $\mathrm{L}$, slightly above the global value of $6.2 \mathrm{~L}$. However, in terms of average consumption per drinker, SSA was far above the worldwide estimate (19.5 and 13.9 L, respectively). Unrecorded adult per capita consumption was relatively high in both sub-regions. A substantial portion of the alcohol consumed was made up of home-made fermented beverages not consumed in other parts of the world. The estimated consumption of unrecorded alcohol was $2.5 \mathrm{~L}$ in Africa D (31\% of total adult per capita alcohol consumption) and $2.7 \mathrm{~L}$ in Africa E (39\% of total adult per capita alcohol consumption). Globally, the proportion of unrecorded consumption was estimated at $27 \%$. Hence, on average, more unrecorded alcoholic beverages are consumed in sub-Saharan African countries than the global average.

The average drinking pattern score was typically high in both regions, that is, more detrimental. However, Africa D had a slightly lower estimate (2.9) compared to Africa E (3.1). This highly prevalent detrimental drinking pattern (e.g., heavy episodic drinking, drinking outside of meals) was the reason why no beneficial effect of alcohol consumption was estimated for SSA. Only one country had a pattern score of two, most were classified as three, and Zimbabwe had the highest score with four. 


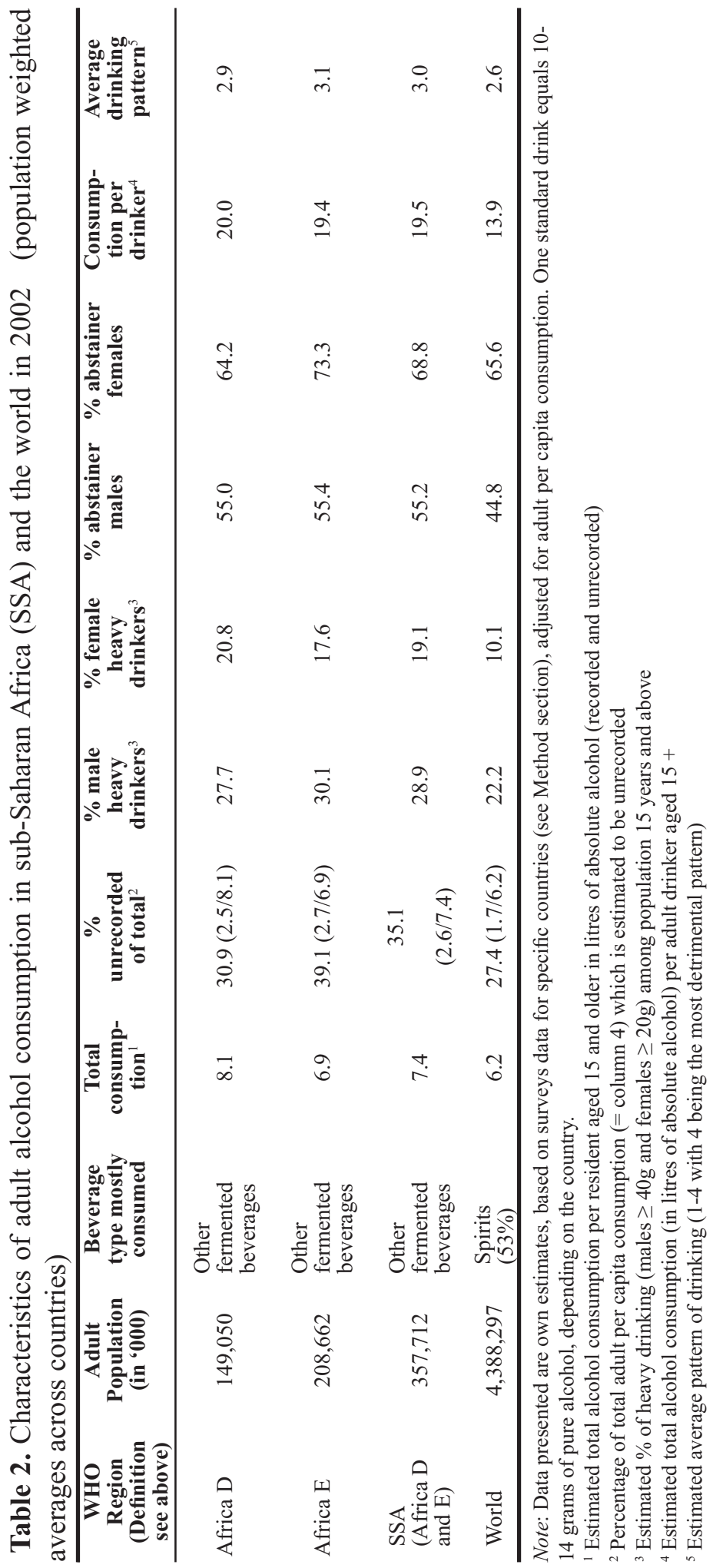


Table 3. Deaths attributable to alcohol consumption in WHO sub-Saharan African Region (SSA), 2002 ('000)

\begin{tabular}{|c|c|c|c|c|c|c|c|c|c|c|c|c|}
\hline \multirow[t]{2}{*}{ Disease Category } & \multicolumn{2}{|c|}{$\overline{\text { AFR D }^{2}}$} & \multicolumn{2}{|c|}{$\overline{A F R} \mathbf{E}$} & \multirow{2}{*}{$\begin{array}{r}\text { SSA } \\
\text { M }\end{array}$} & \multicolumn{7}{|c|}{ World } \\
\hline & $\mathbf{M}^{1}$ & W & M & $\mathbf{W}$ & & $\mathbf{W}$ & $\% \mathbf{M}$ & $\% \mathrm{~W}$ & $\mathbf{M}$ & W & $\% \mathbf{M}$ & $\% W$ \\
\hline $\begin{array}{l}\text { Maternal } \\
\text { and perinatal } \\
\text { conditions (low } \\
\text { birth weight) }\end{array}$ & 0 & 0 & 0 & 0 & 1 & 0 & 0.4 & 0.9 & 1 & 1 & 0.1 & 0.3 \\
\hline Cancer & 8 & 4 & 12 & 4 & 20 & 9 & 11.1 & 17.8 & 361 & 105 & 18.7 & 25.0 \\
\hline Diabetes mellitus & 0 & 0 & 0 & 0 & 0 & 0 & 0.0 & 0.4 & 0 & 1 & 0.0 & 0.2 \\
\hline $\begin{array}{l}\text { Neuropsychiatric } \\
\text { disorders }\end{array}$ & 7 & 3 & 9 & 4 & 16 & 7 & 8.9 & 14.4 & 106 & 25 & 5.5 & 5.9 \\
\hline $\begin{array}{l}\text { Cardiovascular } \\
\text { diseases }\end{array}$ & 7 & 4 & 13 & 3 & 20 & 7 & 10.8 & 13.7 & 452 & 77 & 23.3 & 18.2 \\
\hline $\begin{array}{l}\text { Cirrhosis of the } \\
\text { liver }\end{array}$ & 10 & 4 & 11 & 5 & 21 & 9 & 11.8 & 17.8 & 293 & 77 & 15.2 & 18.2 \\
\hline $\begin{array}{l}\text { Unintentional } \\
\text { injuries }\end{array}$ & 24 & 5 & 45 & 7 & 69 & 12 & 38.0 & 23.8 & 501 & 96 & 25.9 & 22.7 \\
\hline Intentional injuries & 8 & 2 & 26 & 4 & 35 & 6 & 19.1 & 11.2 & 220 & 40 & 11.4 & 9.6 \\
\hline $\begin{array}{l}\text { Total 'detrimental } \\
\text { effects' attributable } \\
\text { to alcohol }\end{array}$ & 65 & 23 & 116 & 27 & 182 & 50 & 100.0 & 100.0 & 1,934 & 421 & 100.0 & 100.0 \\
\hline Diabetes mellitus & 0 & 0 & 0 & 0 & 0 & 0 & 0.0 & 0.0 & -8 & -5 & 7.7 & 3.5 \\
\hline $\begin{array}{l}\text { Cardiovascular } \\
\text { diseases }\end{array}$ & 0 & 0 & 0 & 0 & 0 & 0 & 0.0 & 0.0 & -90 & -130 & 92.3 & 96.5 \\
\hline $\begin{array}{l}\text { Total 'beneficial } \\
\text { effects' attributable } \\
\text { to alcohol }\end{array}$ & 0 & 0 & 0 & 0 & 0 & 0 & 0.0 & 0.0 & -98 & -135 & 100.0 & 100.0 \\
\hline $\begin{array}{l}\text { All alcohol- } \\
\text { attributable net } \\
\text { deaths }\end{array}$ & 65 & 23 & 116 & 27 & 182 & 50 & 100.0 & 100.0 & 1,836 & 287 & 100.0 & 100.0 \\
\hline All deaths & 2,281 & 2,202 & 3,045 & 2,963 & 5,326 & 5,165 & & & 29,891 & 27,138 & & \\
\hline $\begin{array}{l}\text { Percentage of } \\
\text { all net deaths } \\
\text { attributable to } \\
\text { alcohol }\end{array}$ & $2.9 \%$ & $1.0 \%$ & $3.8 \%$ & $0.9 \%$ & $3.4 \%$ & $1.0 \%$ & & & $6.1 \%$ & $1.1 \%$ & & \\
\hline
\end{tabular}

Note: Numbers are rounded to the nearest thousand. Zero (0) indicates fewer than 500 alcohol-attributable deaths in the disease category

${ }^{1} \mathrm{M}=$ men, $\mathrm{W}=$ women

2 excludes Algeria

The distribution of average alcohol consumption across countries in both subregions was heterogeneous. In Nigeria, the most populous country in Africa D with almost $40 \%$ of the total adult population in this sub-region, adult per capita alcohol consumption $(14.1 \mathrm{~L})$ was almost twice as high as the regional average (8.1), and more than twice as high as the global average $(6.2 \mathrm{~L})$. Overall, similar regional abstention rates were estimated for Africa D (59\% for men, $69 \%$ for women) and Africa E (55\% for men, $73 \%$ for women). However, the variation in abstention rates in the sub-regions was quite high. For example, compare Nigeria ( $46 \%$ of men and $55 \%$ of women were abstinent), which had a very high consumption even when applying global standards, with Mali and Senegal, with abstention rates well above $90 \%$.

With regard to the most populous countries in Africa E, average adult per capita alcohol consumption was lower in the Democratic Republic of the Congo (3.2 L) compared to Ethiopia $(5.5 \mathrm{~L})$ or South Africa $(9.1 \mathrm{~L})$. However, the proportion of unrecorded alcohol consumption was markedly higher in Ethiopia 
(more than 80\%). The proportions in South Africa and the Democratic Republic of the Congo were $24 \%$ and $39 \%$, respectively.

Despite relatively high abstention rates, alcohol consumption caused considerable mortality and disease burden in sub-Saharan Africa. In total, 182,000 men and 50,000 women in SSA were estimated to have died prematurely due to alcohol consumption in 2002. Compared to the worldwide mortality burden due to alcohol consumption the two African sub-regions had proportionally lower estimates for men (about half the size of the global estimate) but showed similar estimates for women (Table 3). Men accounted for about three times as much mortality burden due to alcohol compared to women in Africa D, and more than four times in Africa E. These differences were mostly driven by intentional and unintentional injuries, the categories with the most deaths attributable to alcohol among men in both sub-regions. Both types of injuries combined accounted for about half the mortality burden due to alcohol in each sub-region for men. In women, the relative importance of injuries is much less pronounced. The relative contribution of alcohol-attributable injury death estimates in SSA as a whole compared to the world was markedly higher for men and almost equal for women. The relative estimate for cardiovascular disease deaths due to alcohol for men is lower than in the rest of the world, presumably due to the lower life expectancy in SSA. In addition, the lower life expectancy in Africa is reflected in lower mortality burden due to cancer, which also mainly occurs later in life.

Alcohol-attributable YLLs for SSA are shown in Table 4. Sex differences among the two sub-regions for YLLs were slightly more pronounced compared to mortality estimates. Proportionally, YLLs among men were three times higher than for women in Africa D, and five times higher in Africa E. Nevertheless, the proportion of alcohol-attributable YLLs of all YLLs in SSA was about half of those seen worldwide for both sexes. Similar to alcohol-attributable mortality, unintentional and intentional injury categories among men were twice as high in Africa E as in Africa D. The main differences for both sexes between the two sub-regions and also compared to worldwide estimates were the high proportion of intentional injuries in Africa E, more so among men than women. These differences were greatest when considering YLLs, because these deaths occurred at a relatively young age. In addition, premature mortality due to neuropsychiatric disorders in Africa was markedly higher among women from both sub-regions compared to the global proportion of all alcohol-attributable YLLs.

Table 5 shows the distribution of alcoholattributable DALYs in the sub-Saharan African sub-regions in 2002. The proportion of alcoholattributable neuropsychiatric disorders among all DALYs attributable to alcohol in both men and women was much higher in comparison to YLLs, resulting from the fact that alcohol use disorders (e.g., alcohol dependence) and to a lesser degree epilepsy, both of which constitute the majority of alcohol-attributable neuropsychiatric disorders, are less fatal than other chronic disease categories.

Intentional and unintentional injuries accounted for almost $53 \%$ of all alcoholattributable deaths, $64 \%$ of YLLs, and $57 \%$ of DALYs in SSA. The population between 15-44 years was especially affected by alcohol-attributable injury deaths. In 2002, more than two-thirds (70\%) of the all alcoholattributable injury deaths in men and more than half in women occurred in this age group (see Table 6).

\section{DISCUSSION}

The average adult per capita consumption rate in SSA is slightly higher than the global rate, but lower compared to Western Europe. However, taking into account the relatively high abstention rates, average consumption per drinker in SSA (19.5 L) is among the highest in the world. Clearly, what distinguishes SSA from the world average is a detrimental drinking pattern and a high proportion of alcoholattributable intentional injuries, but more so 


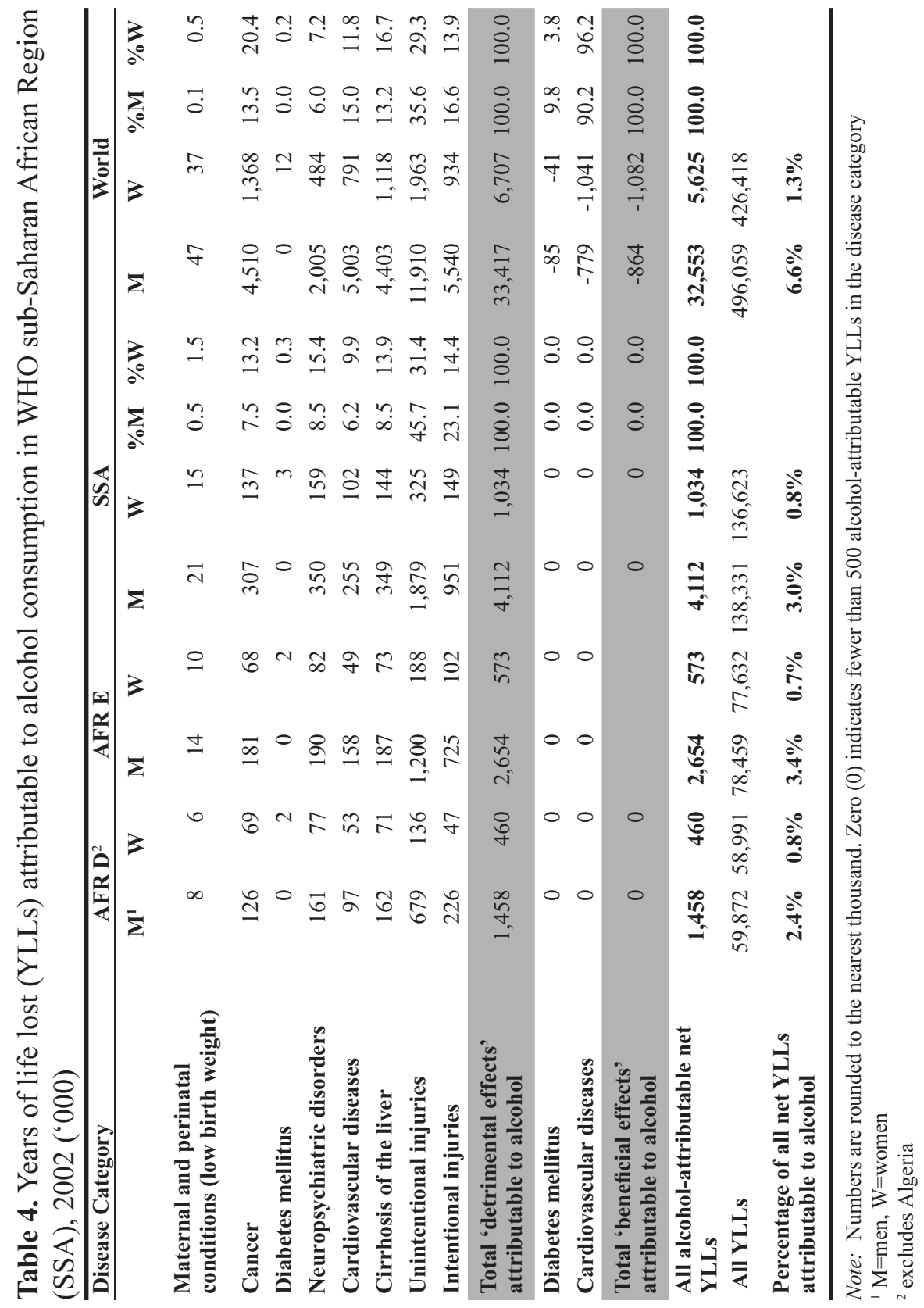




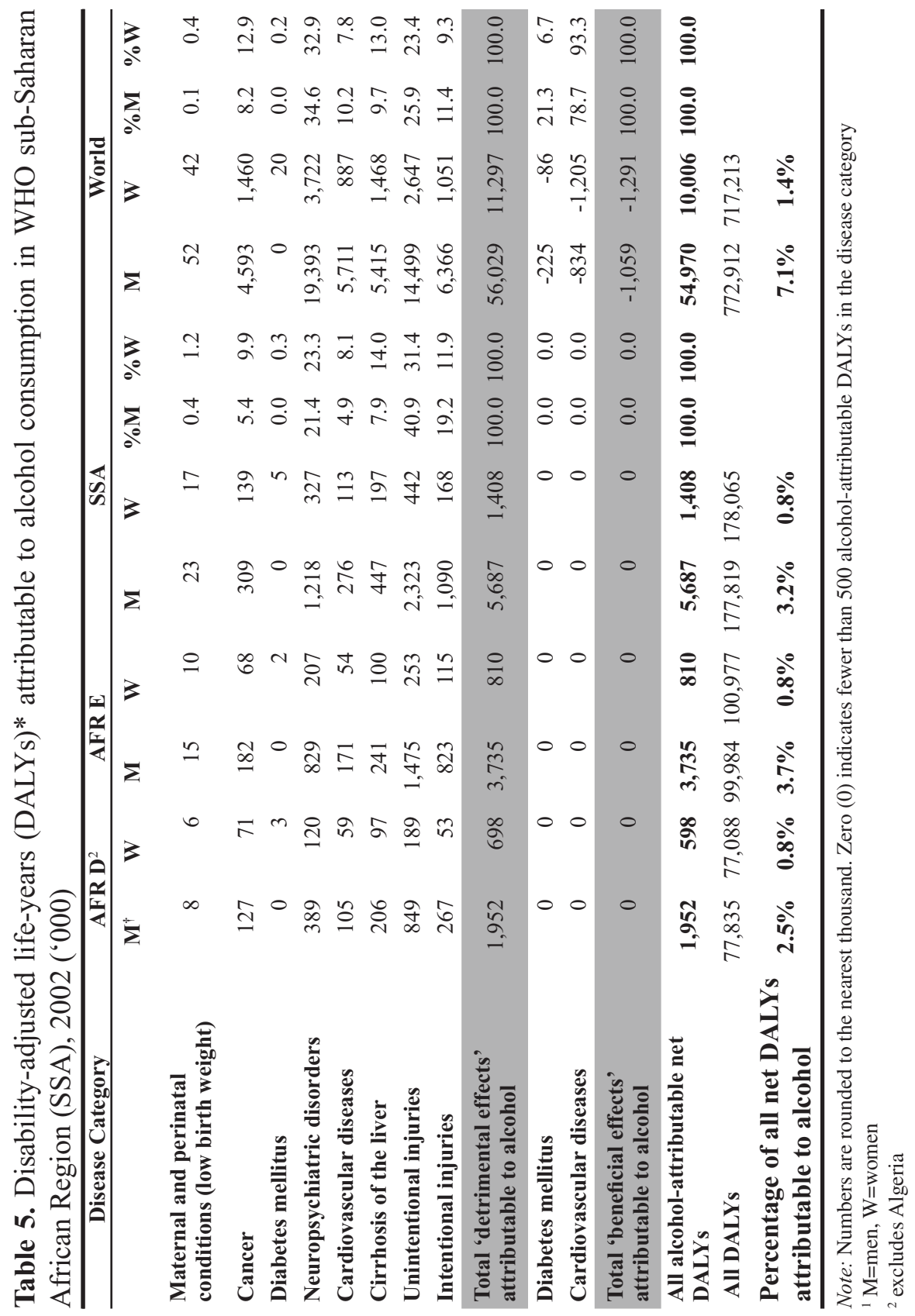


Table 6. Age and sex distribution (\%) of alcohol-attributable injury deaths in WHO subSaharan African Region (SSA) and the world, 2002

\begin{tabular}{|c|c|c|c|c|c|c|c|c|}
\hline \multirow[t]{2}{*}{ Region } & \multicolumn{7}{|c|}{ Age group } & \multirow{2}{*}{$\begin{array}{l}\text { Total alcohol- } \\
\text { attributable } \\
\text { injury deaths }\end{array}$} \\
\hline & 0 to 4 & 5 to 14 & 15 to 29 & 30 to 44 & 45 to 59 & 60 to 69 & $70+$ & \\
\hline \multicolumn{9}{|l|}{ Men } \\
\hline $\mathrm{AFR} \mathrm{D}^{1}$ & 3.6 & 7.8 & 38.9 & 31.4 & 12.4 & 3.6 & 2.3 & 33 \\
\hline AFR E & 3.1 & 5.1 & 40.7 & 28.9 & 14.3 & 4.9 & 3.0 & 71 \\
\hline SSA & 3.2 & 6.0 & 40.1 & 29.7 & 13.7 & 4.5 & 2.8 & 104 \\
\hline World & 1.2 & 1.8 & 32.6 & 31.1 & 19.5 & 7.6 & 6.2 & 721 \\
\hline \multicolumn{9}{|l|}{ Women } \\
\hline AFR D $^{1}$ & 5.8 & 15.9 & 30.0 & 23.5 & 14.7 & 5.4 & 4.6 & 7 \\
\hline AFR E & 6.8 & 14.9 & 27.3 & 23.2 & 15.5 & 6.4 & 5.9 & 11 \\
\hline SSA & 6.5 & 15.3 & 28.3 & 23.3 & 15.2 & 6.0 & 5.4 & 17 \\
\hline World & 2.4 & 3.5 & 21.0 & 24.1 & 20.9 & 10.4 & 17.8 & 136 \\
\hline
\end{tabular}

Note: ${ }^{1}$ excludes Algeria

${ }^{2}$ Numbers are rounded to the nearest thousand.

unintentional injury death, in particular among young men. Our finding that African youth are particularly affected by alcohol-related-harm has also been found in other studies (Parry, 2005; Peltzer, 2003). On the other hand, the relative importance of alcohol-attributable burden of cancer and cardiovascular diseases was not as pronounced as in other regions due to a lower life expectancy generally observed in Africa. The effect of alcohol-related injuries is greatest when measured in YLLs (64\%). It is higher compared to death alone (53\%) because injury deaths usually occur earlier in life. When looking at DALYs (57\%), the proportion is reduced compared to YLL because disease categories that result mostly in morbidity rather than mortality, such as neuropsychiatric disorders, have a stronger effect on DALYs than on YLLs.

The estimates presented in this analysis have several strengths and limitations which should be examined. Clearly, the major strength of the analysis is the standardized methodology developed originally for the CRA, as well as the use of standardized mortality and morbidity estimates (for general methodology to derive these statistics see Mathers et al., 2003). The resulting comparability between risk factors differentiates CRA-based risk factor analyses from other risk factor estimates, including the estimates of the 1990 Global Burden of Disease Study, where results could not be compared between risk factors (Ezzati et al., 2004; for 1990 estimates see Murray \& Lopez, 1999). On the negative side, however, caution should be used when interpreting details of alcohol consumption in SSA. The quality of African estimates was not as reliable as for other regions of the world. Mortality and disability data were taken from $\mathrm{WHO}$, and the quality of these data has been discussed extensively in the literature since the first Global Burden of Disease Study (Cooper, Osotimehin, Kaufman, \& Forrester, 1998). While the overall data availability improved since then, SSA certainly still is the part of the world with the highest uncertainty of data based on lack of birth and child registers in many countries (Mathers et al., 2006; Mathers, Lopez, \& Murray, 2006). For many countries, only partial information on exposure to alcohol was available. Furthermore, the proportion of unrecorded adult per capita alcohol consumption was among the highest estimated worldwide. Unrecorded consumption in Africa is typically made up of traditional homemade alcoholic beverages, in this study mostly labelled as 'other fermented beverages'. These beverages can be produced from a number of agricultural products, including, for example, burukutu, made out of sorghum grains and fermented guinea corn 
in the northern part of Nigeria, and palm wine produced from the sap of the palm tree in the southern part. These types of beverages are not comparable to the categories (beer, wine and spirits) usually used in other parts of the world; they are also mostly consumed by the poor, and vary greatly from region to region within Africa in terms of strength and ingredients (Obot, 2007). Estimates of this alcohol production are usually not covered by official statistics and this adds some uncertainty. For example, survey data on abstention rates in South Africa do not match well with recorded and unrecorded production figures (Schneider et al., 2007). Despite the long history of alcohol use in Africa, epidemiological and clinical data on alcohol consumption and related harm are still scarce (Obot, 2007; Obot, 2000). The risk relations on which we based our estimates of burden of disease (mainly taken from studies conducted in North America and Europe), may not hold true in Africa due to several reasons. First, the effect of alcohol on injuries may be over- or underestimated. These estimates were taken directly form the CRA 2000; however, it seems that these estimates can be quite influenced by culture and context (Rehm et al., 2004). Secondly, for some diseases, such as alcohol-attributable liver cirrhosis, the risk might be different from what it is in other parts of the world due to malnutrition (Bergheim, McClain, \& Arteel, 2005; Caregaro et al., 1996; Everitt, Patel, \& Tewfik, 2007; Isichei, Ikwuagwu, \& Egbuta, 1994). In addition, we did not take into account the role of alcohol on the burden due to infectious diseases, for example HIV. Although alcohol does not play a role in the biological pathway, it seems to be a mediating factor in risky sexual behaviour and therefore enables the transmission of HIV (Mbulaiteye et al., 2000). In addition, heavy drinking may lead to people in HIV treatment not taking their medication properly (Talbot et al., 2002).

The amount per drinker and the pattern in which alcohol is consumed is a major public health concern in Africa that needs more attention than it has received in the past. The detrimental pattern of alcohol consumption common in SSA (and observed elsewhere in the developing world), presents a problem because it also is an indicator of harm to a society and accounts for the fact that no beneficial effect of alcohol consumption was estimated in SSA. In light of the substantial diseases burden due to alcohol in SSA, prevention and treatment of alcohol-related harm should be a major public health priority in this region, and evidencebased interventions should be implemented where possible (see also Room, Babor, \& Rehm, 2005). Parry \& Bennetts (1998) already suggested policies to reduce alcohol-related burden of disease for South Africa. Otherwise, in agreement with economic development, alcohol consumption and its health and social consequences will most likely increase in the future (Room et al., 2003). Research in North America and Western Europe has shown that public policy measures such as tax increases, developing and enforcing drinking-driving laws, restricted licensing of outlets, or brief interventions in the primary care setting are effective and cost-effective interventions (Babor et al., 2003). Some of these measures might produce similar results if implemented in African countries, but because of data quality and availability issues, more research is warranted to guide and evaluate the implementation of intervention measures in SSA.

\section{ACKNOWLEDGMENTS}

The Comparative Risk Assessment (CRA) for Alcohol project was financially supported by the WHO and the Research Institute for Public Health and Addiction, Zürich, Switzerland, a WHO Collaborative Centre. We would like to thank Dr. Charles Parry for latest data on alcohol consumption in South Africa.

\section{REFERENCES}

Babor, T., Caetano, R., Casswell, S., Edwards, G., Giesbrecht, N., Graham, K. et al. (2003). Alcohol: No Ordinary Commodity - Research and Public Policy. Oxford: Oxford University Press. 
Bergheim, I., McClain, C. J., \& Arteel, G. E. (2005). Treatment of Alcoholic Liver Disease. Digestive Diseases, 23, 275-284.

Caregaro, L., Alberino, F., Amodio, P., Merkel, C., Bolognesi, M., Angeli, P. et al. (1996). Malnutrition in alcoholic and virus-related cirrhosis. American Journal of Clinical Nutrition, 63, 602-609.

Cho, E., Smith-Warner, S. A., Ritz, J., van den Brandt, P. A., Colditz, G. A., Folsom, A. R. et al. (2004). Alcohol Intake and Colorectal Cancer: A Pooled Analysis of 8 Cohort Studies. Annals of Internal Medicine, 140, 603-613.

Cooper, R. S., Osotimehin, B., Kaufman, J. S., \& Forrester, T. (1998). Disease burden in sub-Saharan Africa: what should we conclude in the absence of data? Lancet, 351, 208-210.

Corrao, G., Bagnardi, V., Zambon, A., \& La Vecchia, C. (2004). A meta-analysis of alcohol consumption and the risk of 15 diseases. Preventive Medicine, 38, 613619.

English, D., Holman, C., Milne, E., Winter, M., Hulse, G., \& Codde, G. (1995). The quantification of drug-caused morbidity and mortality in Australia, 1995 Canberra, Australia: Commonwealth Department of Human Services and Health.

Everitt, H., Patel, V. B., \& Tewfik, I. (2007). Nutrition and alcoholic liver disease. Nutrition Bulletin, 32, 138-144.

Ezzati, M., Lopez, A. D., Rodgers, A., \& Murray, C. (2004). Comparative quantification of health risks. Global and regional burden of disease attributable to selected major risk factors. (vols. 1) Geneva, Switzerland: WHO.

Giesbrecht, N., Greenfield, T. K., Lemmens, P., \& Österberg, E. (2000). Estimating alcohol consumption: measurement and policy issues related to legal and illegal sources of alcohol. Contemporary Drug Problems, 27, 221-233.

Gmel, G., Rehm, J., \& Kuntsche, E. (2003). Binge drinking in Europe: definitions, epidemiology, and consequences. Sucht, 49, 105-116.
Gureje, O., Degenhardt, L., Olley, B., Uwakwe, R., Udofia, O., Wakil, A. et al. (2007). A descriptive epidemiology of substance use and substance use disorders in Nigeria during the early 21st century. Drug and Alcohol Dependence, 91, 1-9.

Gutjahr, E., Gmel, G., \& Rehm, J. (2001). Relation between average alcohol consumption and disease: an overview. European Addiction Research, 7, 117-127.

Isichei, H. U., Ikwuagwu, P. U., \& Egbuta, J. O. (1994). A Comparative-Study of Alcoholic Patients in Jos, Nigeria, and in Castrop-Rauxel, Germany. Alcohol and Alcoholism, 29, 75-78.

Mathers, C., Bernard, C., Iburg, K., Inoue, M., Ma Fat, D., Shibuya, K. et al. (2003). The Global Burden of Disease in 2002: data sources, methods and results (GPE Discussion Paper No. 54) Geneva, Switzerland: World Health Organization.

Mathers, C., Vos, A., Lopez, A. D., Salomon, J., \& Ezzati, M. (2001). National burden of disease studies: a practical guide. (2 ed.) Geneva, Switzerland: World Health Organization.

Mathers, C., Lopez, A., \& Murray, C. (2006). The burden of disease and mortality by condition: data, methods and results for 2001. In A.Lopez, C. Mathers, M. Ezzati, D. Jamison, \& C. Murray (Eds.), Global Burden Disease and Risk Factors (pp. 45240). Washington/New York: World Bank and Oxford University Press.

Mathers, C., Salomon, J., Ezzati, M., Begg, S., Van der Hoorn, S., \& Lopez, A. (2006). Sensitivity and uncertainty analyses for burden of disease and risk factor estimates. In A.Lopez, C. Mathers, M. Ezzati, D. Jamison, \& C. Murray (Eds.), Global Burden Disease and Risk Factors (pp. 399-426). Washington/New York: World Bank and Oxford University Press.

Mbulaiteye, S. M., Ruberantwari, A., Nakiyingi, J., Carpenter, L., Kamali, A., \& Whitworth, J. (2000). Alcohol and HIV a study among sexually active adults in rural southwest Uganda. International Journal of Epidemiology, 29, 911-915. 
McKee, M. \& Britton, A. (1998). The positive relationship between alcohol and heart disease in eastern Europe: potential physiological mechanisms. Journal of the Royal Society of Medicine, 91, 402-407.

Morojele, N., Flisher.A.J., \& Parry, C. D. H. (2005). Urbanization, youth and substance use in South Africa. In I.S.Obot \& S. Saxena (Eds.), Substance use among young people in urban environments (pp. 103120). Geneva: World Health Organization.

Murray, C. \& Lopez, A. (1999). On the comparable quantification of health risks: lessons from the global burden of disease study. Epidemiology, 10, 594-605.

Murray, C. (1996). Rethinking DALYs. In C. Murray \& A. Lopez (Eds.), The Global Burden of Disease (pp. 1-89). Cambridge, MA: Harvard School of Public Health (on behalf of the WHO and World Bank).

Obot, I. S. (2007). Nigeria: alcohol and society today. Addiction, 102, 519-522.

Obot, I. S. (1993). Drinking behaviour and attitudes in Nigeria: a general population survey. Jos, Nigeria, University of Jos. CDS Monograph.

Obot, I. S. (2005). Substance use among students and out-of-school youth in an urban area of Nigeria. In I.S.Obot \& S. Saxena (Eds.), Substance use among young people in urban environments (pp. 133-146). Geneva: WHO.

Obot, I. S. (2000). The measurement of drinking patterns and alcohol problems in Nigeria. Journal of Substance Abuse, 12, 169-181.

Pan, L. (1975). Alcohol in colonial Africa. Helsinki: Finnish Foundation of Alcohol Studies.

Parry, C. D. \& Bennetts, A. L. (1998). Alcohol Policy and Public Health in South Africa. Oxford: Oxford University Press.

Parry, C. D. H. (2005). South Africa: alcohol today. Addiction, 100, 426-429.

Partanen, J. (1990). Abstinence in Africa. In J.Maula, M. Linblad, \& C. Tigerstedt (Eds.), Alcohol in developing countries (pp. 70-85). Helsinki: Nordic Council for Alcohol and Drug Research.
Peltzer, K. (2003). Drinking motives, behaviour and problems among black South African university students. African Journal of Drug and Alcohol Studies, 2, 1-10.

Puddey, I. B., Rakic, V., Dimmitt, S. B., \& Beilin, L. J. (1999). Influence of pattern of drinking on cardiovascular disease and cardiovascular risk factors - a review. Addiction, 94, 649-663.

Rehm, J. \& Gmel, G. (2001). Applying principles of comparative risk analysis to substance abuse-related burden. European Addiction Research, 7, 95-97.

Rehm, J., Patra, J., Baliunas, D., Popova, S., Roerecke, M., \& Taylor, B. (2006). Alcohol consumption and global burden of disease 2002 Geneva: WHO, Department of Mental Health and Substance Abuse, Management of Substance Abuse (Internal document for the WHO Technical Advisory Group meeting on Alcohol Epidemiology at Geneva, Switzerland).

Rehm, J., Room, R., Monteiro, M., Gmel, G., Graham, K., Rehn, N. et al. (2004). Alcohol Use. In M.Ezzati,A. Lopez, A. Rodgers, \& C. Murray (Eds.), Comparative quantification of health risks: global and regional burden of disease attributable to selected major risk factors (pp. 959-1109). Geneva: WHO.

Rehm, J., Klotsche, J., \& Patra, J. (2007). Comparative quantification of alcohol exposure as risk factor for global burden of disease. International Journal of Methods in Psychiatric Research, 16, 66-76.

Rehm, J., Monteiro, M., Room, R., Gmel, G., Jernigan, D., Frick, U. et al. (2001). Steps towards constructing a global comparative risk analysis for alcohol consumption: determining indicators and empirical weights for patterns of drinking, deciding about theoretical minimum, and dealing with different consequences. European Addiction Research, 7, 138-147.

Rehm, J., Rehn, N., Room, R., Monteiro, M., Gmel, G., Jernigan, D. et al. (2003a). The global distribution of average volume of alcohol consumption and patterns of drinking. European Addiction Research, 9, 147-156. 
Rehm, J., Room, R., Monteiro, M., Gmel, G., Graham, K., Rehn, N. et al. (2003b). Alcohol as a risk factor for global burden of disease. European Addiction Research, 9, 157-164.

Rehm, J., Sempos, C. T., \& Trevisan, M. (2003). Average volume of alcohol consumption, patterns of drinking and risk of coronary heart disease - a review. Journal of Cardiovascular Risk, 10, 15-20.

Ridolfo, B. \& Stevenson, C. (2001). The Quantification of Drug-Caused Mortality and Morbidity in Australia 1998 Canberra, Australia: Australian Institute of Health and Welfare.

Room, R., Jernigan, D., Carlini Cotrim, B., Gureje, O., Makela, K., Marshall, M. et al. (2003). Alcohol in developing societies: a public health approach. Helsinki and Geneva: Finnish Foundation for Alcohol Studies and WHO.

Room, R., Babor, T., \& Rehm, J. (2005). Alcohol and public health: a review. Lancet, 365, 519-530.

Schneider, M., Norman, R., Parry, C., Bradshaw, D., Plüddemann, A., \& South African Comparative Risk Assessment Collaborating Group (2007). Estimating the burden of disease attributable to alcohol in South Africa in 2000. South African Medical Journal, 97, 664-672.

Talbot, E. A., Kenyon, T. A., Moeti, T. L., Hsin, G., Dooley, L., El-Halabi, S. et al.
(2002). HIV risk factors among patients with tuberculosis - Botswana 1999. International Journal of STD \& AIDS, 13, 311-317.

United Nations. (2004). World Population Prospects: The 2004 Revision. United Nations Department of Economic and Social Affairs. New York, United Nations, Population Division.

Walter, S. D. (1976). The estimation and interpretation of attributable risk in health research. Biometrics, 32, 829849.

Walter, S. D. (1980). Prevention for multifactorial diseases. American Journal of Epidemiology, 112, 409-416.

World Health Organization (2000). The World Health Report 2000: Health systems: Improving performance Geneva: WHO.

World Health Organization (2002). World Health Report 2002: Reducing risks, promoting healthy life Geneva: WHO.

World Health Organization (2004). Global Status Report on Alcohol 2004 Geneva: WHO, Department of Mental Health and Substance Abuse.

World Health Organization (2006). Global Alcohol Database (GAD). http://www3. who.int/whosis/alcohol/alcohol_apc data.cfm?path=whosis, alcohol,alcohol apc,alcohol_apc_data\&language $=$ english [On-line]. 